\title{
Safety evaluation and cardiovascular effect of additional use of spironolactone in hemodialysis patients: a meta-analysis
}

This article was published in the following Dove Press journal:

Drug Design, Development and Therapy

\author{
Qing Zeng' \\ XiaoDuo Zhou ${ }^{2}$ \\ Ge Xu'
}

'Department of Cardiology, The First Affiliated Hospital of Guangxi Medical University, Nanning, People's Republic of China; ${ }^{2}$ Department of Cardiology, The

Zhen Zhou University Affiliated Nanyang Central Hospital, Nanyang, People's Republic of China
Correspondence: $\mathrm{Ge} \mathrm{Xu}$

Department of Cardiology, The First

Affiliated Hospital of Guangxi Medical

University, Nanning 53002I, People's

Republic of China

Tel +86I 8978862591

Email 40217224I@qq.com
Objective: To evaluate the safety and cardiovascular effect of low-dose spironolactone administration in end-stage renal failure patients undergoing hemodialysis coupled with conventional treatment.

Methods: We conducted a systematic search for clinical trials on the safety and cardiovascular effect of additional low-dose spironolactone in hemodialysis patients. The search was performed on PubMed, EMBASE, Cochrane Library, and CBM databases. Relevant references (up to February 2016) were retrieved and subsequent results analyzed with a randomeffects model or a fixed-effects model.

Results: We identified nine trials with a total sample size of 765 patients. The results did not indicate significant differences regarding safety and serum potassium levels (mean difference $[\mathrm{MD}]=0.23, P=0.09$ ) between the two treatment options. However, patients receiving lowdose spironolactone exhibited improvements in left venticular mass index (LVMI) (standardized mean difference $=-0.58, P<0.00001$ ) and left ventricular ejection fraction (LVEF) $(\mathrm{MD}=4.91, P<0.0001)$ with an additional decrease in systolic blood pressure $(\mathrm{MD}=-6.97$, $P=0.0001)$ and diastolic blood pressure $(\mathrm{MD}=-4.01, P=0.007)$. Furthermore, the clinical $(\mathrm{OR}=0.4, P=0.0003)$ or cardiovascular and cerebrovascular-related $(\mathrm{OR}=0.4, P=0.002)$ mortality was significantly lower among those patients.

Conclusion: These results indicated that additional use of low-dose spironolactone associated with conventional treatment does not have a significant impact on serum potassium levels in hemodialysis patients. What's more, it might exert a protective effect on the cardiovascular system by optimizing LVMI, improving LVEF, decreasing arterial blood pressure and reducing events-related mortality. Further large sample size studies are needed to support these findings.

Keywords: Spironolactone, hemodialysis, safety, cardiovascular protection, meta-analysis

\section{Introduction}

Heart disease is extremely recurrent in dialysis patients and coronary artery disease, hypertension and left ventricular failure account for the majority of cases in this subgroup of patients. ${ }^{1-5}$ Patients with end-stage renal failure (ESRF) and on hemodialysis often die of heart disease at a much higher rate (20 to 40 times) than the general population. ${ }^{6-8}$ According to the United States Renal Data System, cardiovascular disease accounts for more than $44 \%$ of all mortalities. ${ }^{6-8}$

Several studies conducted on ESRD patients indicated a significant increase in aldosterone. $^{3,9,10}$ Aldosterone is thought to play a role in the development of 
hypertension, vascular structure alteration, vascular smooth muscle hypertrophy, endothelial dysfunction, renal injury, proteinuria, left ventricular remodeling, collagen synthesis, and myocardial fibrosis. With excess aldosterone, both renal and extrarenal mineralocorticoid receptors are activated further exacerbating the effect of angiotensin II and other products of the renin-angiotensinaldosterone system (RAAS). ${ }^{11,12}$ Excessive activation of RAAS contributes to the development of cardiac hypertrophy and myocardial fibrosis ${ }^{13}$ and leads to complex pathophysiological effects that may result in hypertension, heart failure, and other cardiovascular disorders. ${ }^{11,12,14-26}$

Currently, the most relevant pharmacological agents that block the RAAS are angiotensin-converting enzyme (ACE) inhibitors and AT1 receptor blockers (ARBs). Aldosterone has been overlooked as a consequential RAAS mediator and a relevant factor in target organ injury in spite of the widespread usage of RAAS blockers. ${ }^{11,27}$ Consequently, mineralocorticoid receptor antagonist (MRA) might have benefits for target organ injury mitigation.

Prior studies ${ }^{28-31}$ on the impact of spironolactone, a potent competitive mineralocorticoid receptor, on patients with heart failure and myocardial infarction without renal insufficiency have shown favorable outcomes. Nevertheless, safety risks still exist due to its effect on sodium and potassium levels. To date, several clinical studies have actively explored the safety and protective effects of spironolactone in dialysis patients. However, significant differences in outcome indicators and limitations such as small sample size or a limited follow-up period can be observed among those studies. Therefore, it is difficult to form a unified conclusion. Subsequently, the current study applied a systematic evaluation approach and meta-analysis methods to evaluate the safety and protective effect of spironolactone in hemodialysis patients aiming to provide clinical evidence for the optimization of patients prognosis.

\section{Methods}

\section{Data sources and search strategy}

The present meta-analysis was performed according to The Preferred Reporting Items for Systematic Reviews and Meta-analyses (PRISMA) guidelines. ${ }^{32,33}$ PubMed, EMBASE, Cochrane Library, and CBM databases were searched using the following keywords: Spironolactone, Antisterone, Renal Dialysis, Renal Replacement, End Stage Renal Disease, Renal Insufficiency, and Kidney Failure. No restrictions were imposed on language and date of publication. The final search was run on February 01, 2016. Additional searches were performed based on retrieved articles to identify studies omitted by our primary search strategy.

\section{Study selection}

The study selection diagram is shown in Figure 1. All randomized controlled trials (RCTs) and quasi RCTs conducted on a population of adult CKD patients requiring dialysis and with a dialysis period of more than one month were included. Randomized, crossover studies were also considered for inclusion.

Exclusion criteria were as follows: studies with kidney transplant recipients (ESRD), RCTs with different outcomes than the ones of interest, studies lacking a comparable control or placebo, reviews, meeting abstracts, and case-only studies.

\section{Endpoint definition}

Endpoints of this study included serum potassium levels $(\mathrm{mmol} / \mathrm{L})$, changes in heart structure and function, blood pressure levels, All-cause mortality, cardiovascular and cerebrovascular (CCV) mortalities, Heart failure, Stroke, New or recurrent Acute myocardial infarction (AMI), Aortic dissection and sudden death.

\section{Data extraction and quality assessment}

Data from all included studies were extracted by two independent reviewers using a standardized dataextraction protocol. Disagreements were resolved by consensus. Data extracted from the study included: 1. study characteristics (title, first author name, year of publication, design, and duration); 2. participant characteristics (age, sex, the presence of other chronic diseases (hypertension, cardiac insufficiency, diabetes), the frequency of dialysis treatment, type of medication); 3. the nature of treatment and intervention (MRA type, dose, frequency, and followup duration); 4. the outcome (serum/plasma potassium levels, changes in heart structure and function, blood pressure, All-cause mortality, Cardiovascular mortality). The quality of each RCT was evaluated using the Cochrane risk of bias instrument which primarily assesses the randomization and allocation concealment, the blinding process of individuals involved in the trial, the completeness of follow-up, and the outcome. Each study outcomes were classified as low risk of bias, unclear, or high risk of bias. The quality assessments of the two none-randomized 


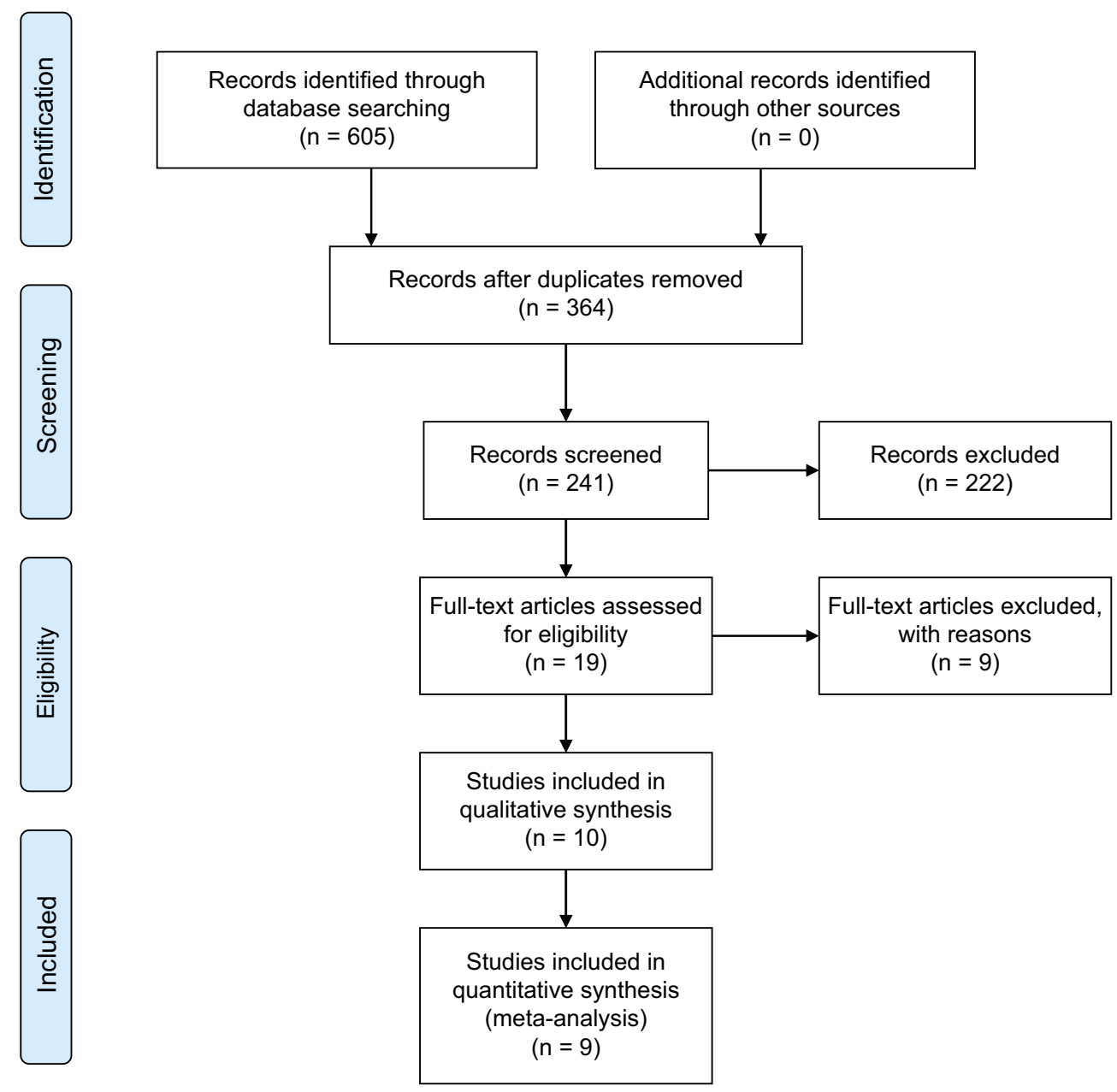

Figure I Selection process of studies included in the meta-analysis.

studies were performed using The Newcastle-Ottawa Scale with few modifications to match the needs of this metaanalysis. $^{34,35}$ This scoring system uses the following aspects of study design to assess quality: patient selection, comparability of study groups, and assessment of outcome. High-quality studies were defined as studies that have achieved five or more stars on the modified Newcastle-Ottawa Scale.

\section{Data synthesis and statistical analysis}

The statistical analysis was conducted on the Cochrane Review Manager (RevMan version 5.3). Continuous outcomes were analyzed using mean differences (MDs), standardized mean differences (SMDs) and dichotomous outcomes were analyzed using pooled odds ratio (OR) to combine different tests and measurement scales within each domain. Overall effect estimates were calculated for all analyses using inverse variance weighted fixed-effects analysis with 95\% confidence intervals (CIs). Standard deviations (SDs) were calculated using the following formula: $\mathrm{SD}=$ square root $[(\mathrm{SD}$ pretreatment $) 2+$ (SD posttreatment $) 2-(2 \mathrm{R} \times \mathrm{SD}$ pre-treatment $\times \mathrm{SD}$ post-treatment $)]$, assuming a correlation coefficient of $(\mathrm{R})=0.5$.

Heterogeneity among studies was identified using a standard $\chi 2$ test and a $P$-value (two-sided) based on the Cochran $\mathrm{Q}$ statistic. ${ }^{36} \mathrm{I}^{2}$ index, as the percentage of variation across studies, was used to assess heterogeneity with an $\mathrm{I}^{2}$ value of $25 \%, 50 \%$ or $75 \%$ representing low, moderate, or high heterogeneity, respectively. ${ }^{37}$ The fixed effect model was used for analysis in cases where the heterogeneity analysis indicated an $\mathrm{I}^{2}<25 \%$. The source of heterogeneity and the stability of the results were further evaluated for an $\mathrm{I}^{2}$ value of $25 \% \leq \mathrm{I} 2<50 \%$. The random effect model was used for analysis when 
$\mathrm{I}^{2} \geq 50 \%$. Subgroup analysis or sensitivity analysis methods further explored the sources of heterogeneity and explained possible causes. We planned to construct a funnel plot to evaluate the risk of publication bias provided that the number of included studies was sizeable (more than ten).

\section{Results}

\section{Study selection and characteristics}

Of the 605 studies identified by our primary search, 19 articles were retrieved after initial assessment for detailed evaluation. Nine of those met the inclusion criteria and were incorporated in the final analysis (Figures 1 and 2). Tables 1 and 2 summarizes the characteristics of those studies. In summary, seven randomized controlled trials and two non-randomized controlled trials with a sample size of 765 patients and an average follow-up period of 2 weeks to 3 years were included in this meta-analysis. The risk of bias among included trials was

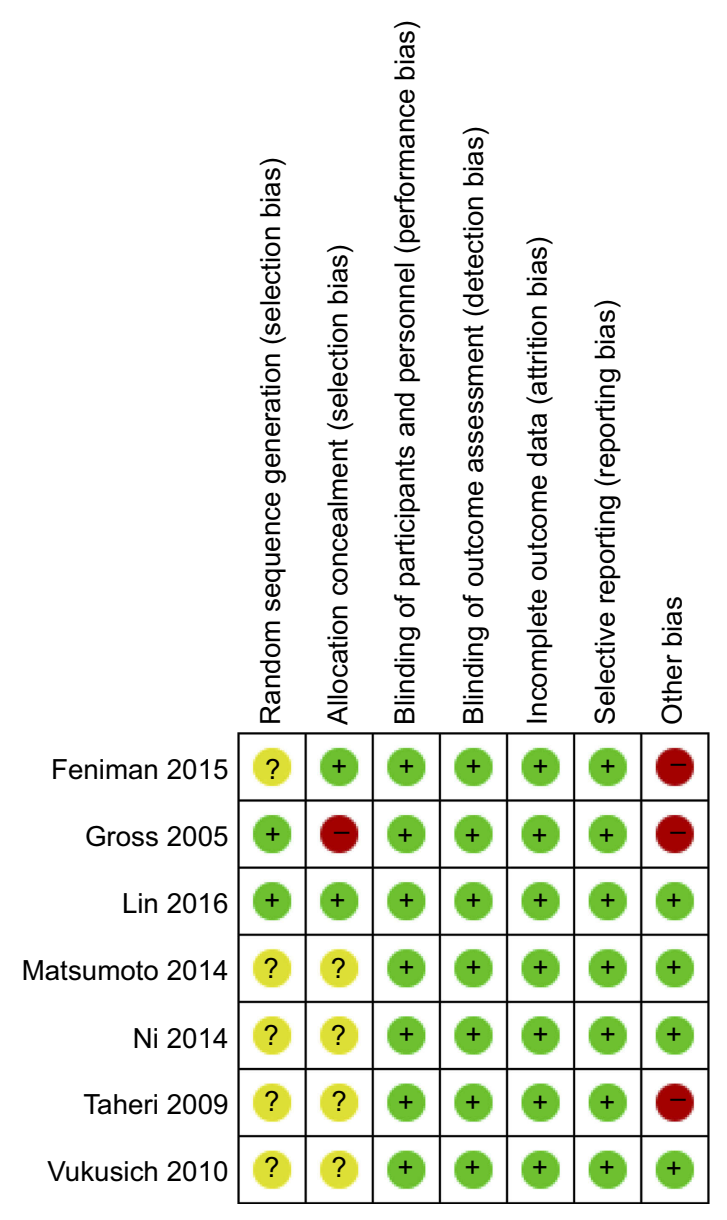

Figure 2 Quality of studies included in the meta-analysis. Red, high risk of bias; green, low risk of bias; yellow, unknown risk of bias. generally low. Two studies ${ }^{38,39}$ scored 5 or more stars on the modified Newcastle-Ottawa Scale.

More detailed informations on the number of studies involved and sample sizes for each outcome are as follows: serum potassium levels, 7 studies (spironolactone, 200 patients; control,202 patients); ${ }^{38-43}$ LVMI, 4 studies (spironolactone, 138 patients; control, 137 patients); $;^{39,40,43,44}$ LVEF, 4 studies (spironolactone, 138 patients; control, 137 patients) ${ }^{39,40,43,44}$ BP, 5 studies (spironolactone, 101 patients; control, 105 patients); ${ }^{39,42,44-46}$ All-cause mortality, 3 studies (spironolactone, 285 patients; control, 293 patients) ${ }^{40,41,43} \mathrm{CCV}$ events, 2 studies (spironolactone, 277 patients; control, 285 patients). ${ }^{40,41}$

\section{Serum potassium levels}

Substantial heterogeneity in serum potassium levels was observed among studies with a significant effect seen in the spironolactone group ( $\mathrm{MD}=0.23,95 \% \mathrm{CI}[-0.03$, $0.49], P=0.09$ ) (Figure 3 ). We carefully checked the extracted data, reviewed the characteristics of included studies, and concluded that heterogeneity might be partly due to two studies: Taheri $2009^{43}$ and Lin $2016 .^{42}$ Therefore, we conducted a fixed-effect subgroup analysis by removing those two studies. ${ }^{42,43}$ As demonstrated in Figure 4, no significant treatment effect was observed in the spironolactone group $(\mathrm{MD}=0,95 \% \mathrm{CI}[-$ $0.18,0.18], P=0.98$ ).

\section{LVMI}

Compared with control, the addition of spironolactone significantly decreased the LVMI ( $\mathrm{SMD}=0.58,95 \% \mathrm{CI}$ $[-0.82,-0.334], P<0.00001$ ) (Figure 5).

\section{LVEF}

As indicated by the results, additional spironolactone treatment elevated the LVEF significantly (MD $=4.91,95 \% \mathrm{CI}$ $[2.58,7.24], P<0.0001)$. No significant heterogeneity was observed (Figure 6).

\section{Blood pressure}

The results indicated that additional spironolactone significantly decreased the systolic blood pressure ( $\mathrm{MD}=-6.97$, 95\%CI [ $-10.56,-3.37], P=0.0001$ ) (Figure 7) and diastolic blood pressure $(\mathrm{MD}=-4.01,95 \% \mathrm{CI}[-6.90,-$ 1.12], $P=0.007$ ) of the treatment group (Figure 11). Secondary analysis of the data using a random effects model showed a downward trend in SBP in the spironolactone group $(\mathrm{MD}=-5.34,95 \% \mathrm{CI}[-11.36,0.68]$, $P=0.08$ ) (Figure 8). 
Table I Characteristics of 9 clinical trials included in the meta-analysis

\begin{tabular}{|c|c|c|c|c|c|c|c|}
\hline Study, year & Study design & $\begin{array}{l}\text { Spironolactone } \\
\text { usage }\end{array}$ & $\begin{array}{l}\text { Hemodialysis } \\
\text { frequency }\end{array}$ & $\begin{array}{l}\text { Follow } \\
\text { time }\end{array}$ & $\begin{array}{l}\text { Cardiac } \\
\text { function } \\
\text { III-IV }\end{array}$ & $\begin{array}{l}\text { Oliguria, } \\
\text { no urine }\end{array}$ & Outcome \\
\hline $\begin{array}{l}\text { Feniman, } \\
2015^{44}\end{array}$ & $\begin{array}{l}\text { Random, placebo } \\
\text { control, double } \\
\text { blind }\end{array}$ & $\begin{array}{l}12.5 \mathrm{mg} \text { daily } \\
\text { ( } 2 \text { weeks) } \\
\text { then } 25 \mathrm{mg} \text { daily }\end{array}$ & None & 6 months & $0 \%$ & None & $\begin{array}{l}\text { Serum potassium } \\
\text { levels, LVMI, LVEF, } \\
\text { BP }\end{array}$ \\
\hline $\begin{array}{l}\text { Gross, } \\
2005^{45}\end{array}$ & $\begin{array}{l}\text { Random, placebo } \\
\text { control, cross }\end{array}$ & $50 \mathrm{mg}$ semiweekly & Triweekly & 2 weeks & None & $100 \%$ & $\begin{array}{l}\text { Serum potassium } \\
\text { levels, BP }\end{array}$ \\
\hline Lin, $2016^{40}$ & $\begin{array}{l}\text { Random, placebo } \\
\text { control, double } \\
\text { blind }\end{array}$ & $25 \mathrm{mg}$ daily & Triweekly & 2 years & $0 \%$ & $\begin{array}{l}\text { Spironolacton } \\
68 \% \\
\text { control } 64 \%\end{array}$ & $\begin{array}{l}\text { Serum potassium } \\
\text { levels, LVMI, LVEF, } \\
\text { All-cause mortality, } \\
\text { CCV mortality }\end{array}$ \\
\hline $\begin{array}{l}\text { Matsumoto, } \\
2014^{41}\end{array}$ & Random, crontrol & $25 \mathrm{mg}$ daily & Triweekly & 3 years & None & None & $\begin{array}{l}\text { All-cause mortality, } \\
\mathrm{CCV} \text { mortality }\end{array}$ \\
\hline $\mathrm{Ni}, 2014^{42}$ & $\begin{array}{l}\text { Random, placebo } \\
\text { control, double } \\
\text { blind }\end{array}$ & $25 \mathrm{mg}$ daily & Triweekly & 12 weeks & None & $100 \%$ & $\begin{array}{l}\text { Serum potassium } \\
\text { levels, BP }\end{array}$ \\
\hline $\begin{array}{l}\text { Sandan, } \\
2003^{38}\end{array}$ & $\begin{array}{l}\text { Non-random, } \\
\text { unblind }\end{array}$ & $\begin{array}{l}12.5 \mathrm{mg} \text { triweekly } \\
(2 \text { weeks) } \\
25 \mathrm{mg} \text { triweekly }\end{array}$ & Triweekly & 4 weeks & $0 \%$ & $\begin{array}{l}\text { Spironolacton } \\
86 \% \\
\text { control } 0 \%\end{array}$ & $\begin{array}{l}\text { Serum potassium } \\
\text { levels }\end{array}$ \\
\hline $\begin{array}{l}\text { Taheri, } \\
2009^{43}\end{array}$ & $\begin{array}{l}\text { Random, placebo } \\
\text { control, double } \\
\text { blind }\end{array}$ & $25 \mathrm{mg}$ triweekly & Triweekly & 6 months & $100 \%$ & None & $\begin{array}{l}\text { Serum potassium } \\
\text { levels, LVMI, LVEF }\end{array}$ \\
\hline $\begin{array}{l}\text { Vukusich, } \\
2010^{46}\end{array}$ & $\begin{array}{l}\text { Random, placebo } \\
\text { control }\end{array}$ & $50 \mathrm{mg}$ triweekly & Triweekly & 2 years & None & None & BP, CIMT \\
\hline Liang, 2011 ${ }^{39}$ & $\begin{array}{l}\text { Non-random, } \\
\text { unblind }\end{array}$ & $25 \mathrm{mg}$ triweekly & Triweekly & 3 months & $100 \%$ & None & $\begin{array}{l}\text { Serum potassium } \\
\text { levels, LVMI, LVEF, } \\
\text { BP }\end{array}$ \\
\hline
\end{tabular}

Abbreviations: CCV, cardiovascular and cerebrovascular; LVMI, left ventricular mass index; LVEF, left ventricular ejection fraction.

The subgroup analysis indicated that the SBP of the spironolactone group was considerably lowered in Subgroup1 $[\mathrm{MD}=-10.51,95 \% \mathrm{CI}(-15.04,-5.97), P<$ 0.00001 ](Figure 9); meanwhile, there was no significant treatment effect in the subgroup $2[\mathrm{MD}=-1.00,95 \% \mathrm{CI}$ $(-6.89,4.89), P=0.74]$ (Figure 10).

\section{All-cause mortality}

Treatment with spironolactone was associated with a significant reduction in all-cause mortality $[\mathrm{OR}=0.4$, $95 \% \mathrm{CI}(0.24,0.66), P=0.0003]$ (Figure 12).

\section{CCV mortality}

The spironolactone group showed a significant reduction in $\mathrm{CCV}$ mortality $[\mathrm{OR}=0.4,95 \% \mathrm{CI}(0.22,0.72), P=0.002]$ (Figure 13).

\section{Discussion}

Our analysis included a total of 765 patients in nine studies, with seven being randomized controlled trials and two non- randomized controlled trials. The results indicated that additional use of low-dose spironolactone associated with conventional treatment does not significantly increase serum potassium levels in hemodialysis patients. Conversely, it might exert a protective effect on their cardiovascular system by optimizing LVMI and improving LVEF.

Mineralocorticoid receptors are present in major organs such as the brain, heart, blood vessels and kidneys, and interestingly, there is evidence suggesting the production of aldosterone within their tissues. ${ }^{1}$ Therefore, the activation of local mineralocorticoid receptors by aldosterone has a significant effect on the cardiovascular system. ${ }^{1,2}$ The existence of "aldosterone escape phenomenon" has been clarified with the widespread usage of ACEI/ARB in clinical settings. ${ }^{11,27}$ Several studies ${ }^{28-31,47,48}$ have confirmed that the addition of MRA coupled with conventional treatments (including ACEI/ARB drugs) can significantly improve the long-term survival rate of patients with heart failure and myocardial infarction. 


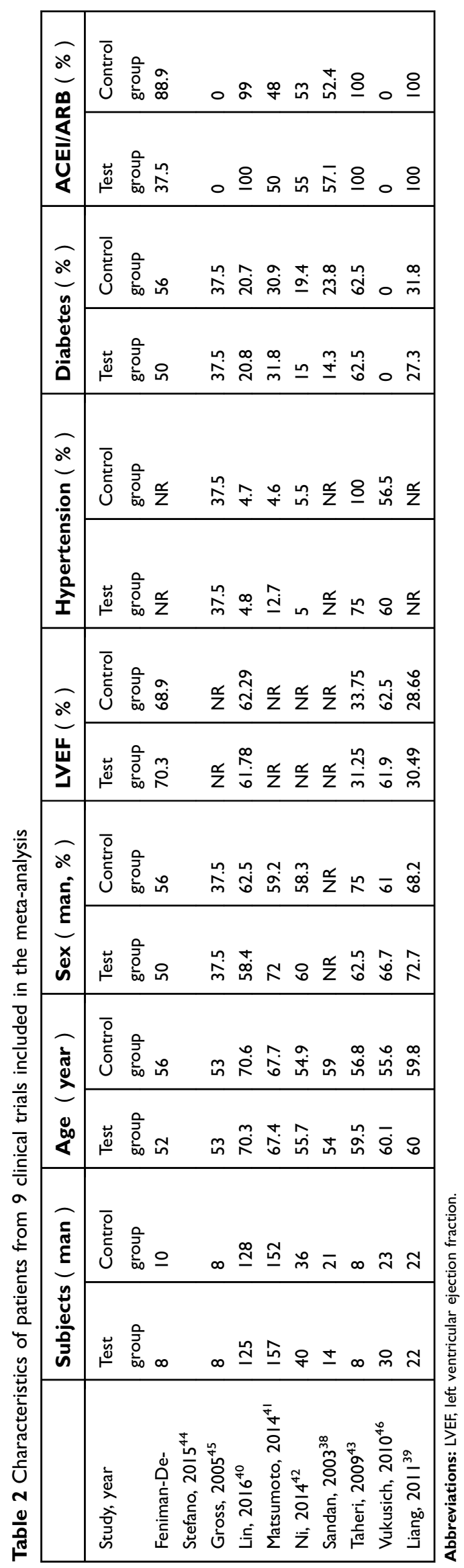




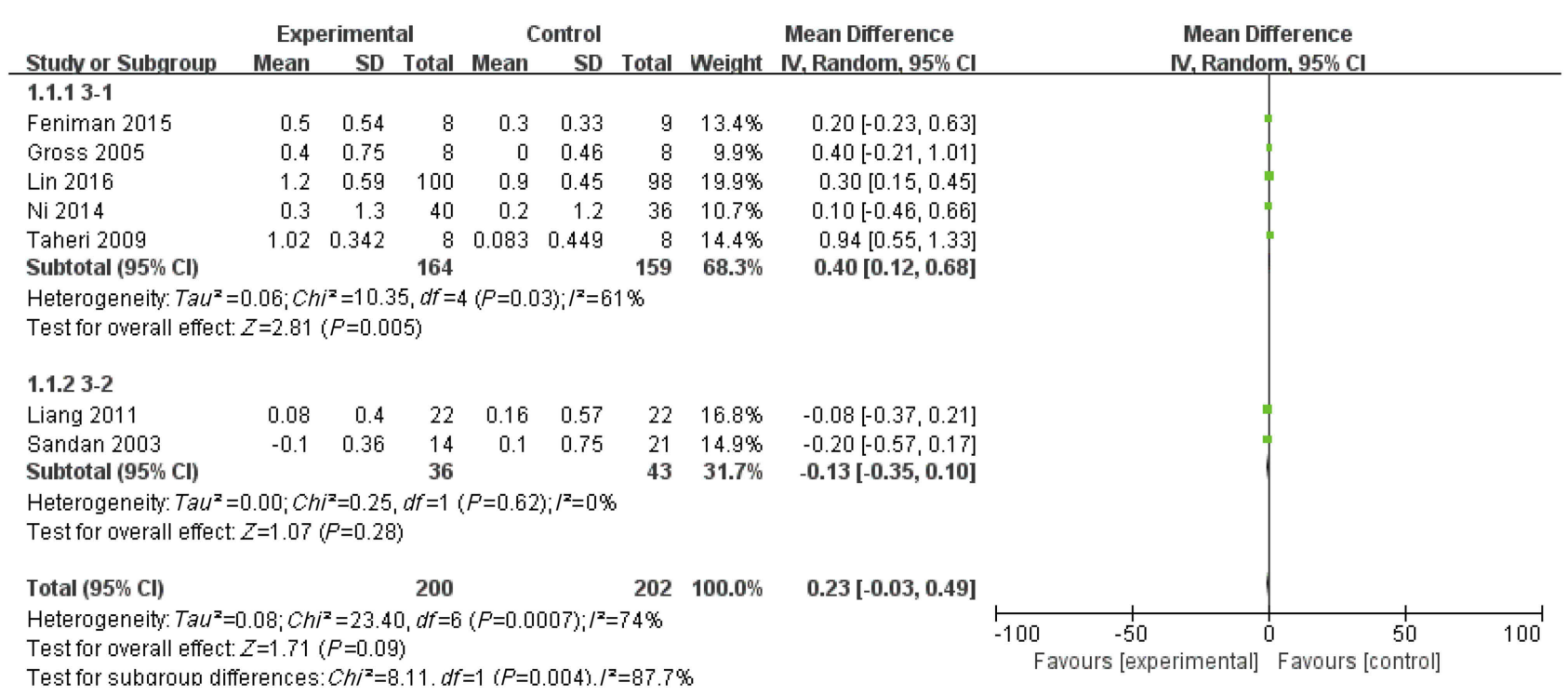

Figure 3 Forest plot for changes of serum potassium level.

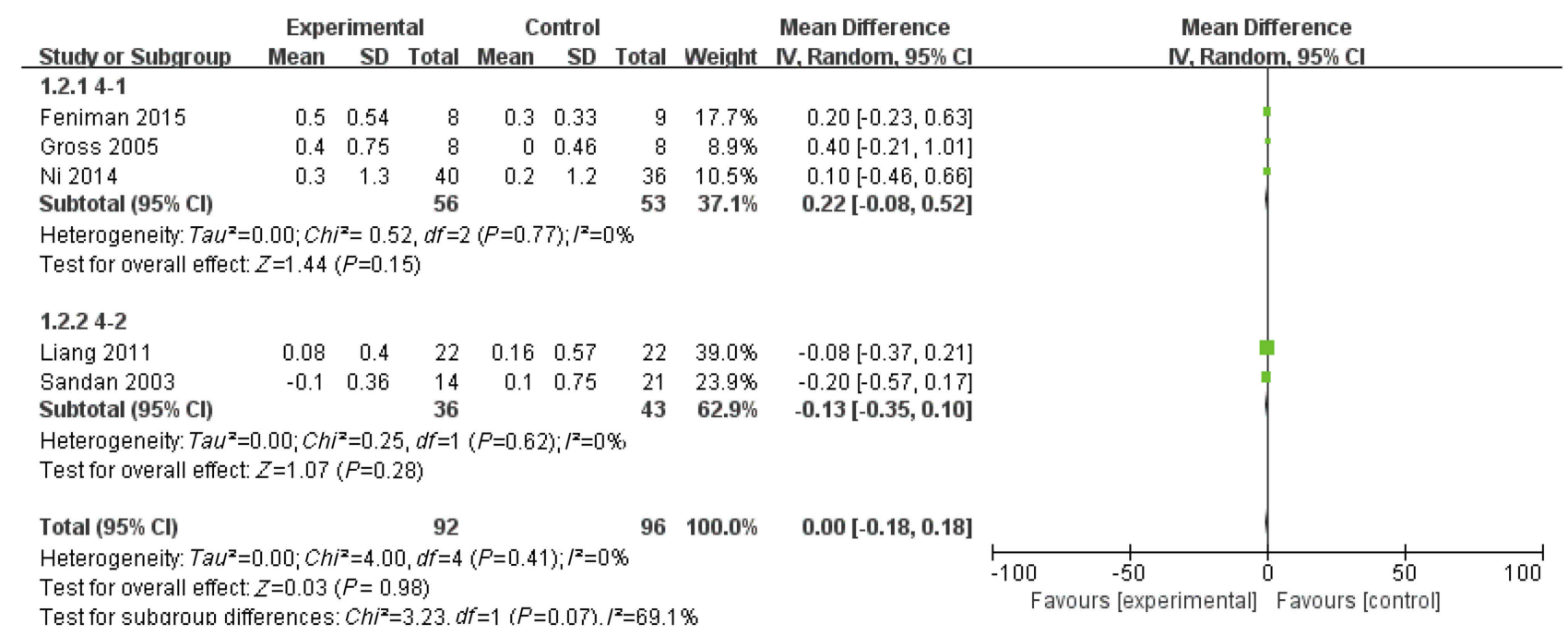

Figure 4 Forest plot for changes of serum potassium level after sensitivity analysis.

However, fluctuations in blood potassium levels and hyperkalemia are likely to occur in patients with renal insufficiency. ${ }^{49}$ Another study showed that the blood potassium balance relied primarily on regular dialysis and timely adjustment of dialysate ion concentration in the ESRD hemodialysis population. ${ }^{50}$

In earlier studies, ${ }^{38,39,43,45,46}$ the administration of spironolactone was timely adjusted, and it was usually administered after hemodialysis to avoid a short-term increase in blood potassium due to oral spironolactone. However, recent studies ${ }^{40-42,44}$ on regular hemodialysis patients with a daily dosage of $25 \mathrm{mg}$ of spironolactone did not indicate a significant increase in mean potassium levels after a follow-up period of 3 months to 2 years. These findings are consistent with the results of the RALES study ${ }^{29}$ suggesting that daily usage of $25 \mathrm{mg}$ of spironolactone is safe in this subgroup.

A previous meta-analysis with 28 eligible studies ${ }^{49}$ found that the use of MRA is associated with a higher risk of hyperkalemia. Meanwhile, another study ${ }^{51}$ indicated that a higher potassium intake might significantly increase the risk of death in long-term HD patients. Therefore, education on risks related to potassium intake is crucial for hemodialysis patients especially those taking spironolactone.

The estimated prevalence of hypertension in patients with chronic kidney disease but not undergoing dialysis is $70 \%$. Of these, $75 \%$ are treated with antihypertensive medications with only $36 \%$ achieving a blood pressure 


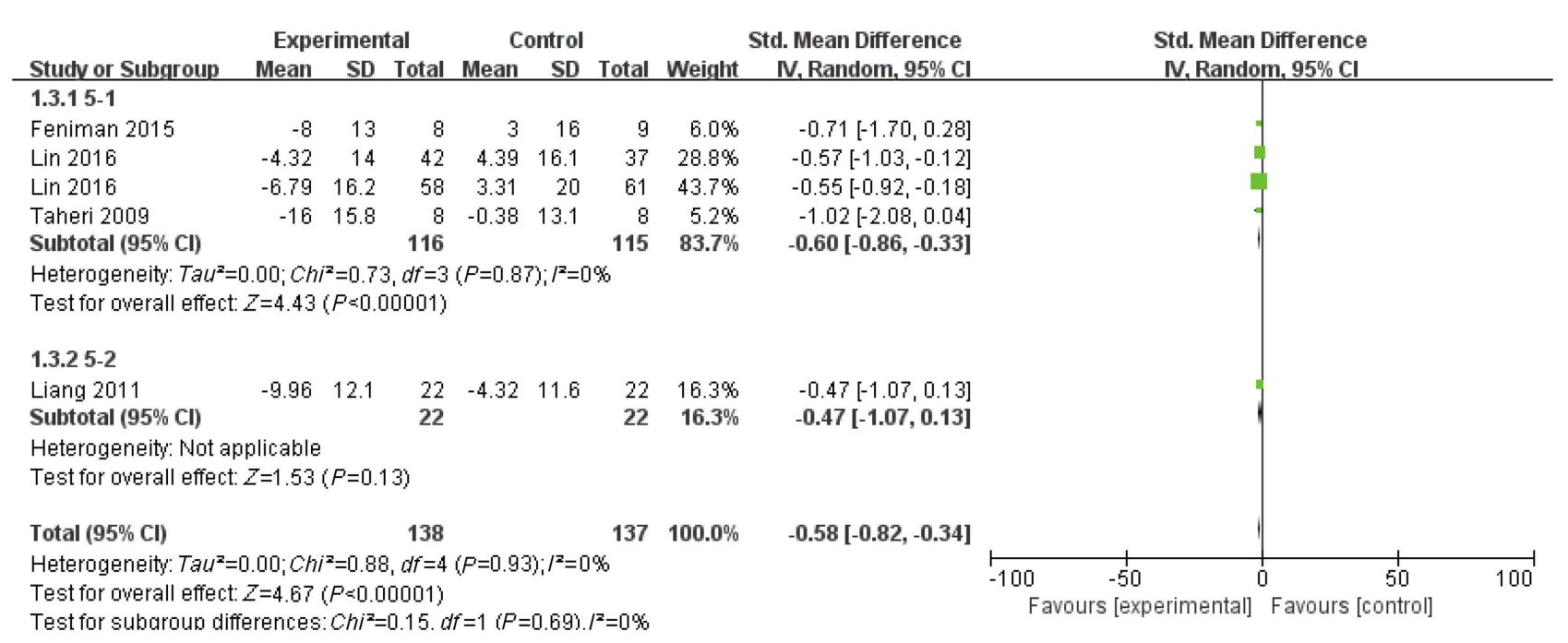

Figure 5 Forest plot for LVMI.

Abbreviation: LVMI, left ventricular mass index.

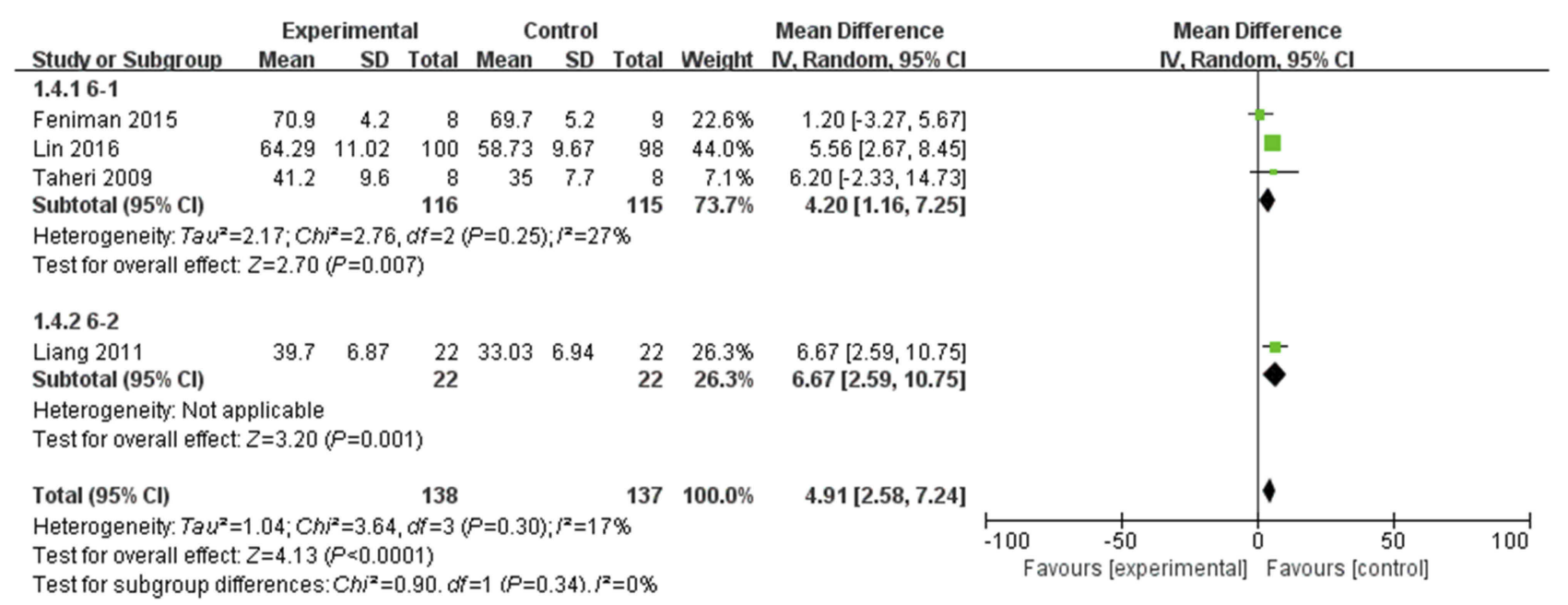

Figure 6 Forest plot for LVEF.

Abbreviation: LVEF, left ventricular ejection fraction.

goal of 140/90 mmHg. ${ }^{52}$ Several studies ${ }^{42,45}$ indicated that administration of spironolactone utilizes a non-diuretic mechanism to decrease pre-dialysis systolic blood pressure in oligo-anuric hemodialysis patients.

Increased common carotid artery intima-media thickness (CCA-IMT) has been associated with an increase in myocardial infarction and stroke risks. Interestingly, fifty milligrams of spironolactone thrice weekly has been shown to significantly reduce the progression of CIMT in HD patients. ${ }^{53-55}$ Here, we indicate that blocking MR has a direct effect on vascular remodeling independent of BP.

The Hammer ${ }^{56}$ trial is a prospective, randomized, placebo-controlled, double-blind, parallel group, and a multi- centered study investigating the effect of spironolactone (50 mg daily) on maintenance hemodialysis patients. The endpoints included changes in LV geometry and function, office and 24-h ambulatory blood pressure, cardiac arrhythmias, vascular function parameters, and measurements of heart failure and quality of life. MiREnDa will provide highly relevant insights into the cardiac and vascular effects as well as the safety of spironolactone in dialysis patients.

The present meta-analysis has several limitations. Firstly, the small sample size and a limited number of clinical trials might make our results susceptible to bias. The second limitation is the lack of long-term studies. 


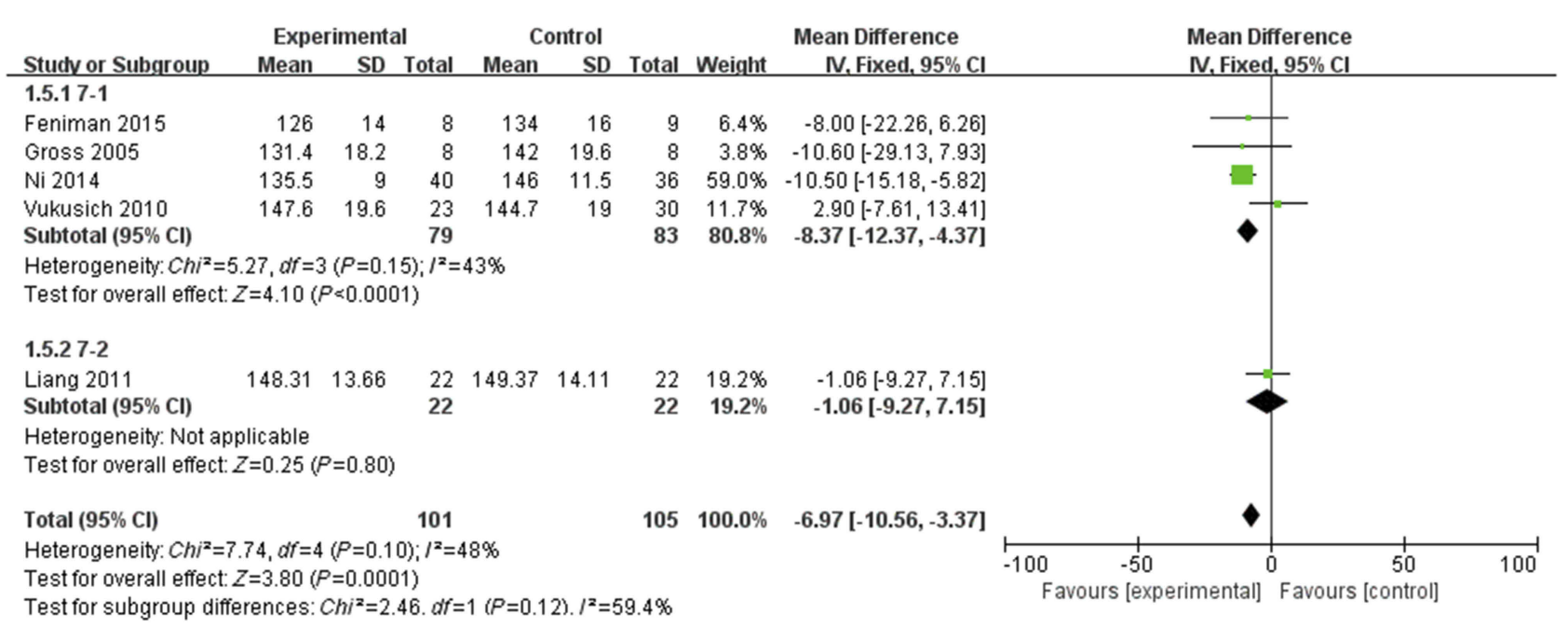

Figure 7 Forest plot for SBP with fixed-effect model.

Abbreviation: SBP, systolic blood pressure.

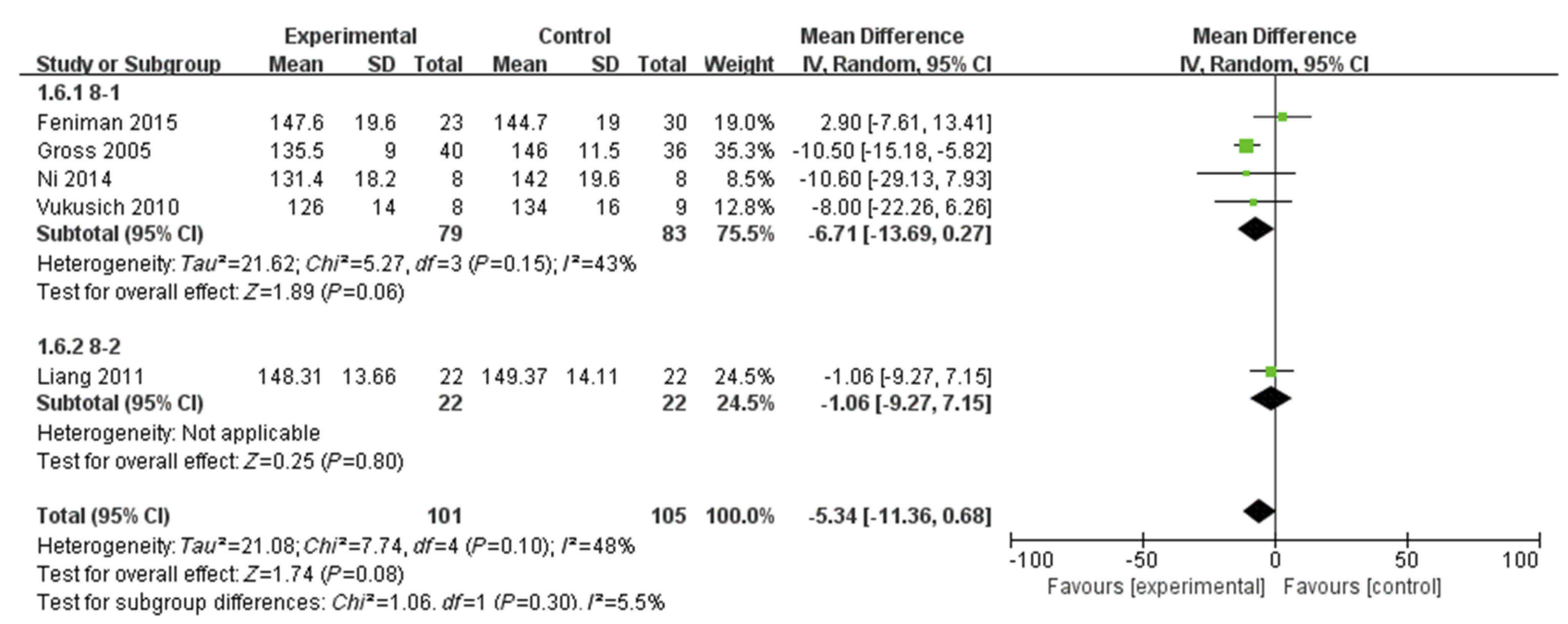

Figure 8 Forest plot for SBP with random-effect model.

Abbreviation: SBP, systolic blood pressure.

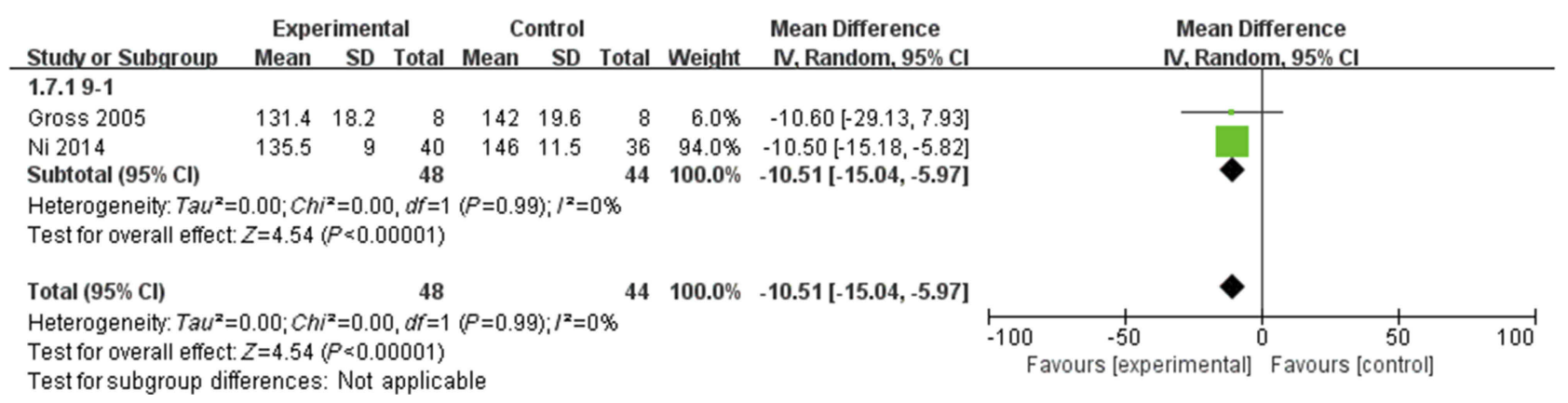

Figure 9 Forest plot for subgroupl analysis of SBP.

Abbreviation: SBP, systolic blood pressure.

For example, only 5 included studies were long-term studies ( $>6$ months), among which, three concluded that spironolactone provided a long-term beneficial effect. Thirdly, the dosage of spironolactone varied between studies making the establishment of a maximum safe dose much harder. Fourthly, even 


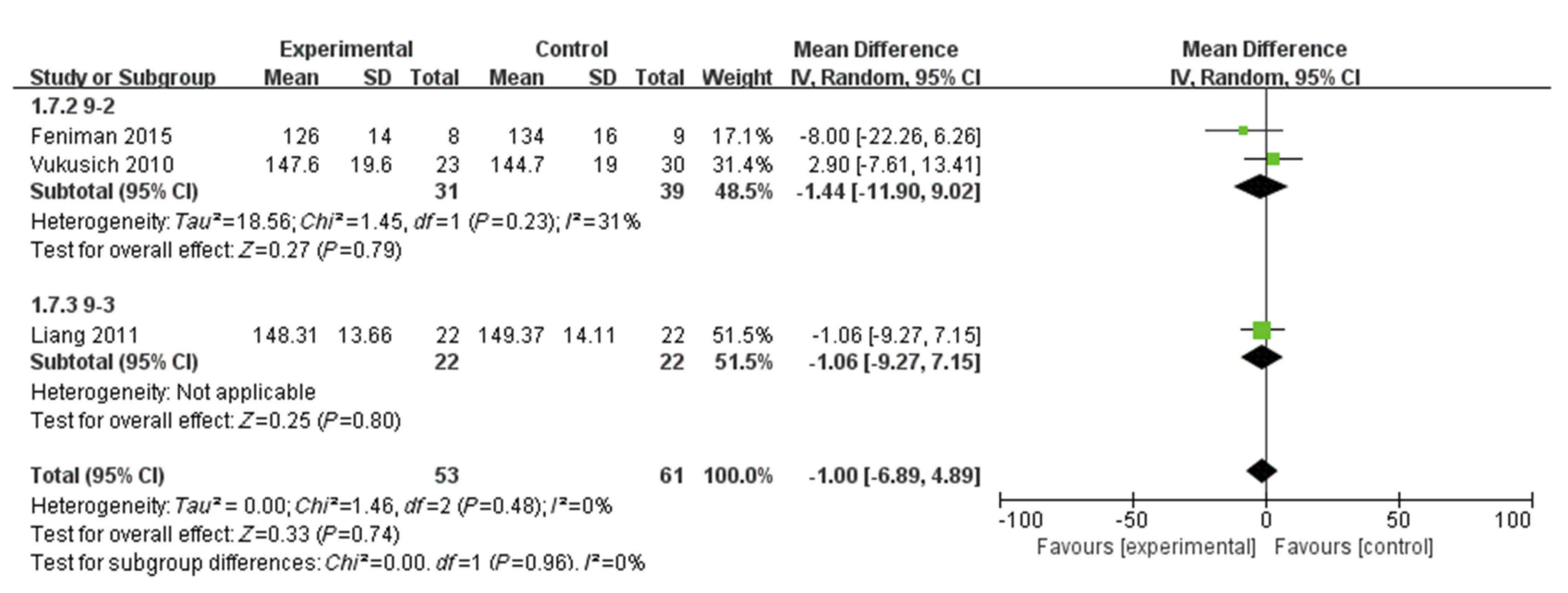

Figure 10 Forest plot for subgroup2 analysis of SBP.

Abbreviation: SBP, systolic blood pressure.

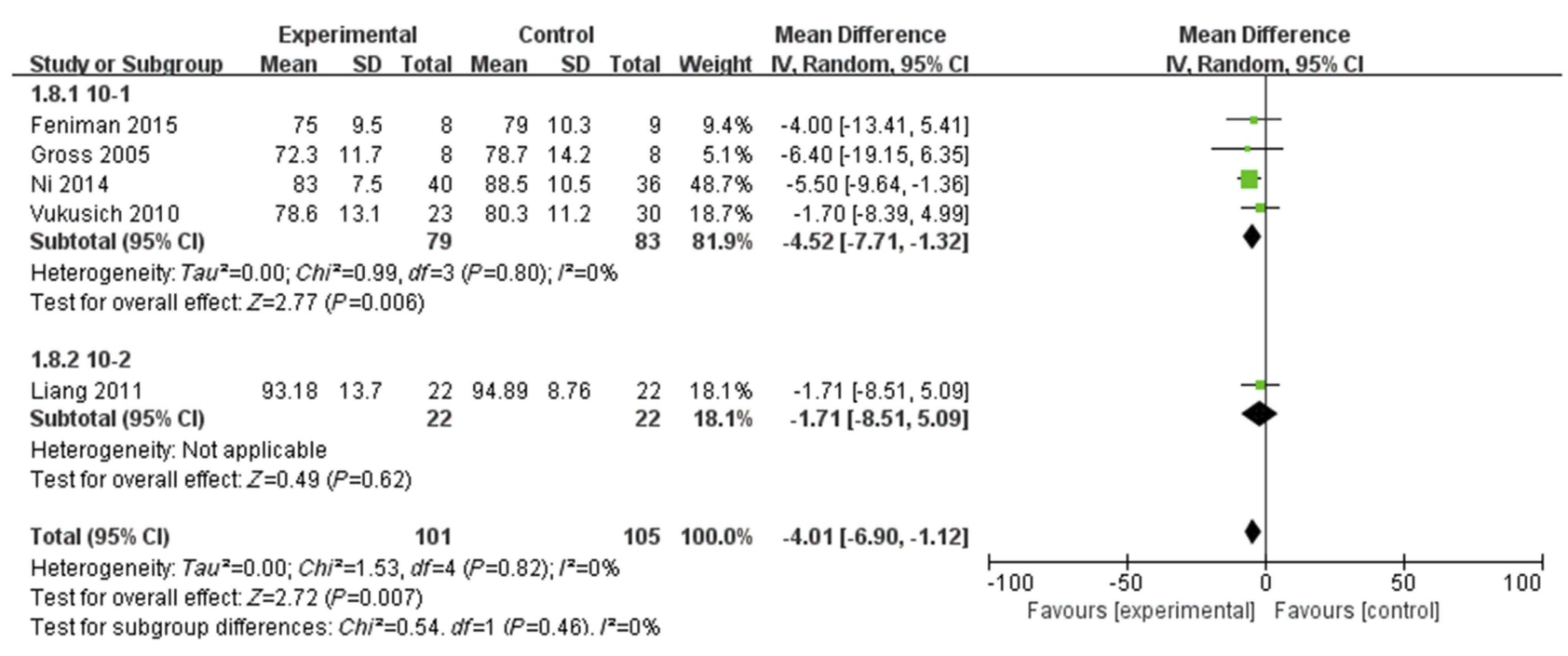

Figure I I Forest plot for DBP.

Abbreviation: DBP, diastolic blood pressure.

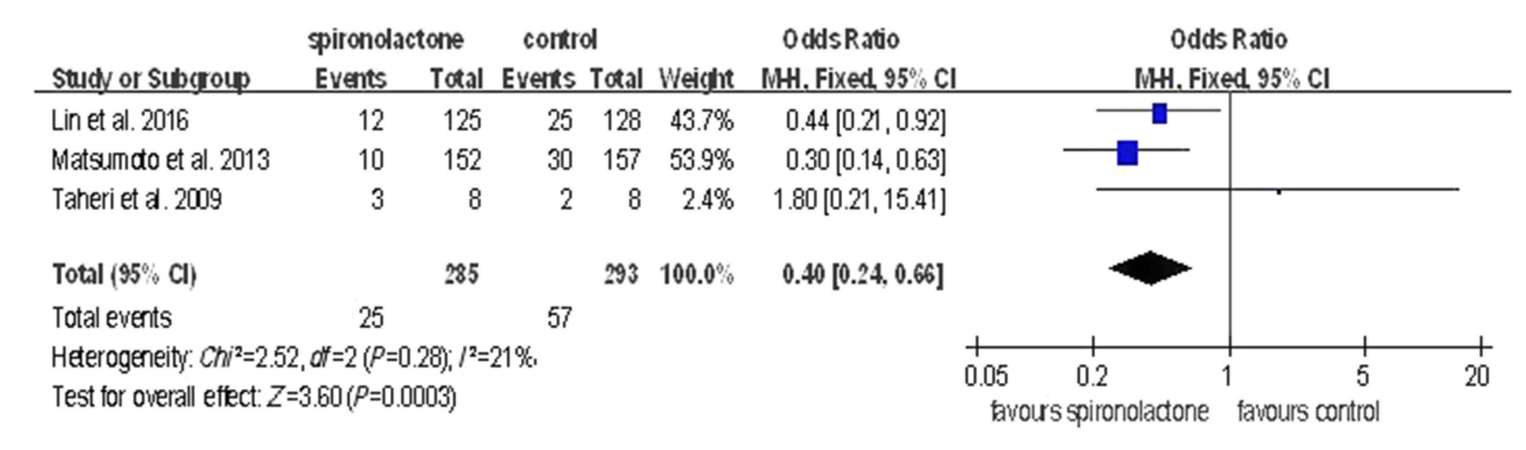

Figure 12 Forest plot for mortality caused by any clinical event.

though some studies have reported changes in blood pressure before and after follow-up, blood pressure was not considered as a primary outcome. Therefore, there may be differences in the control of external factors affecting blood pressure in each group, which in turn might impact the final result. In summary, metaanalysis conclusions still need to be demonstrated by additional high-quality, large-sampled clinical studies. 


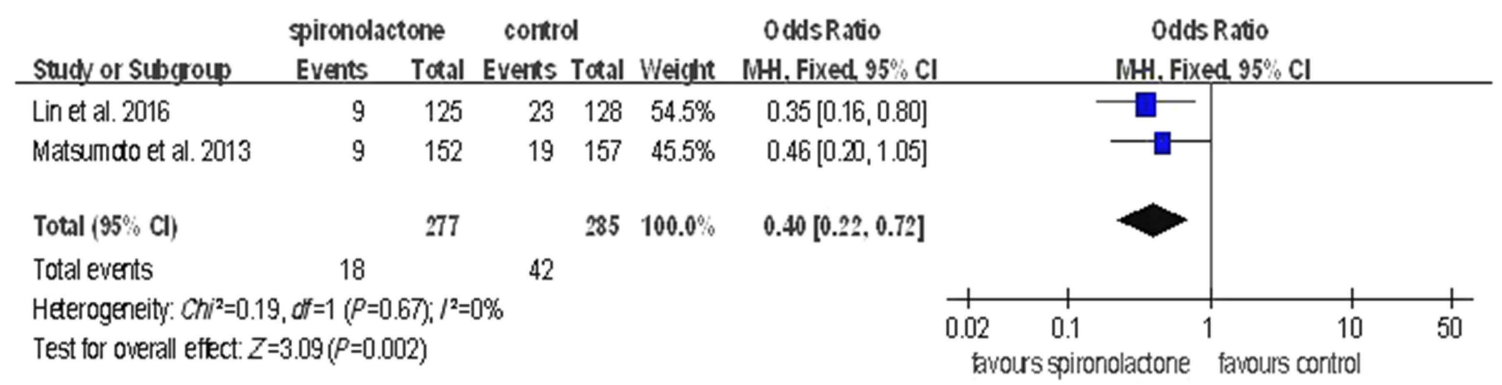

Figure 13 Forest plot for mortality caused by CCV events.

Abbreviation: CCV, cardiovascular and cerebrovascular.

\section{Conclusion}

This study indicated that the additional use of low-dose spironolactone exerts a protective effect on the cardiovascular system of hemodialysis patients by optimizing LVMI, improving LVEF, decreasing arterial blood pressure and reducing clinical or CCV-related mortality. Additionally, its usage did not significantly increase serum potassium levels in those patients.

\section{Disclosure}

The authors report no conflicts of interest in this work.

\section{References}

1. Hussain S, Dreyfus DE, Marcus RJ, et al. Is spironolactone safe for dialysis patients? Nephrol Dial Transplant. 2003;18(11):2364-2368. doi:10.1093/ndt/gfg413

2. Ritz E, Dikow R, Adamzcak M, et al. Congestive heart failure due to systolic dysfunction: the Cinderella of cardiovascular management in dialysis patients[C]//Seminars in dialysis. Blackwell Sci Inc. 2002;15 (3):135-140.

3. Ritz E, Dikow R, Adamzcak M, et al. Congestive heart failure due to systolic dysfunction: the Cinderella of cardiovascular management in dialysis patients[C]//Seminars in dialysis. Malden, US: Blackwell Sci Inc. 2002;15(3):135-140.

4. Szczech LA, Reddan DN, Owen WF Jr, et al. Differential survival after coronary revascularization procedures among patients with renal insufficiency. Kidney Int. 2001;60(1):292-299. doi:10.1046/j.15231755.2001.00799.x

5. Herzog CA, Ma JZ, Collins AJ. Comparative survival of dialysis patients in the United States after coronary angioplasty, coronary artery stenting, and coronary artery bypass surgery and impact of diabetes. Circulation. 2002;106(17):2207-2211.

6. Herzog CA, Ma JZ, Collins AJ. Poor long-term survival after acute myocardial infarction among patients on long-term dialysis. $N$ Engl J Med. 1998;339(12):799-805. doi:10.1056/NEJM199809173391203

7. Silberberg JS, Barre PE, Prichard SS, Sniderman AD. Impact of left ventricular hypertrophy on survival in end-stage renal disease. Kidney Int. 1989;36(2):286-290.

8. Collins AJ, Li S, Ma JZ, Herzog C. Cardiovascular disease in end-stage renal disease patients. Am J Kidney Dis. 2001;38(4):S26S29. doi:10.1053/ajkd.2001.27392

9. Sato A, Funder JW, Saruta T. Involvement of aldosterone in left ventricular hypertrophy of patients with end-stage renal failure treated with hemodialysis. Am J Hypertens. 1999;12(9):867-873.
10. Clark BA, Shannon C, Brown RS, Gervino EV. Extrarenal potassium homeostasis with maximal exercise in end-stage renal disease. $J \mathrm{Am}$ Soc Nephrol. 1996;7(8):1223-1227.

11. Struthers AD. Aldosterone escape during angiotensin-converting enzyme inhibitor therapy in chronic heart failure. J Card Fail. 1996;2(1):47-54.

12. Naruse M, Tanabe A, Sato A, et al. Aldosterone breakthrough during angiotensin II receptor antagonist therapy in stroke-prone spontaneously hypertensive rats. Hypertension. 2002;40(1):28-33.

13. Bader M. Role of the local renin-angiotensin system in cardiac damage: a minireview focussing on transgenic animal models. J Mol Cell Cardiol. 2002;34(11):1455-1462.

14. Struthers AD, MacDonald TM. Review of aldosterone-and angiotensin II-induced target organ damage and prevention. Cardiovasc Res. 2004;61(4):663-670. doi:10.1016/j.cardiores.2003.11.037

15. MacFadyen RJ, Barr CS, Struthers AD. Aldosterone blockade reduces vascular collagen turnover, improves heart rate variability and reduces early morning rise in heart rate in heart failure patients. Cardiovasc Res. 1997;35(1):30-34.

16. Duprez DA, De Buyzere ML, Rietzschel ER, et al. Inverse relationship between aldosterone and large artery compliance in chronically treated heart failure patients. Eur Heart J. 1998;19(9):1371-1376.

17. Rocha R, Chander PN, Khanna K, Zuckerman A, Stier CT. Mineralocorticoid blockade reduces vascular injury in stroke-prone hypertensive rats. Hypertension. 1998;31(1):451-458.

18. Kannel WB. Fifty years of Framingham study contributions to understanding hypertension. $J$ Hum Hypertens. 2000;14(2):83. doi:10.1038/sj.jhh.1000949

19. Ferrario CM, Flack JM. Pathologic consequences of increased angiotensin II activity. Cardiovasc Drugs Ther. 1996;10(5):511-518.

20. MacKenzie SM, Clark CJ, Fraser R, et al. Expression of 11 beta-hydroxylase and aldosterone synthase genes in the rat brain. $J$ Mol Endocrinol. 2000;24(3):321-328.

21. Bonvalet JP, Alfaidy N, Farman N, Lombès M. Aldosterone: intracellular receptors in human heart. Eur Heart J. 1995;16(suppl_N):92-97.

22. Kornel L. Colocalization of 11ß-hydroxysteroid dehydrogenase and mineralocorticoid receptors in cultured vascular smooth muscle cells. Am J Hypertens. 1994;7(1):100-103.

23. Coirini H, Mari A, De Nicola AF, et al. Further studies of brain aldosterone binding sites employing new mineralocorticoid and glucocorticoid receptor markers in vitro. Brain Res. 1985;361 (1-2):212-216.

24. Klag MJ, Whelton PK, Randall BL, et al. Blood pressure and end-stage renal disease in men. $N$ Engl J Med. 1996;334(1):13-18. doi:10.1056/NEJM199601043340103

25. Mizuno Y, Yoshimura M, Yasue H, et al. Aldosterone production is activated in failing ventricle in humans. Circulation. 2001;103(1):72-77.

26. Hatakeyama H, Miyamori I, Fujita T, et al. Vascular aldosterone. Biosynthesis and a link to angiotensin II-induced hypertrophy of vascular smooth muscle cells. J Biochem Physiol. 1994;269 (39):24316-24320. 
27. Lakkis J, Lu WX, Weir MR. RAAS escape: a real clinical entity that may be important in the progression of cardiovascular and renal disease. Curr Hypertens Rep. 2003;5(5):408-417.

28. Pitt B, Zannad F, Remme WJ, et al. The effect of spironolactone on morbidity and mortality in patients with severe heart failure. $N$ Engl J Med. 1999;341(10):709-717. doi:10.1056/NEJM199909023411001

29. Zannad F, Alla F, Dousset B, et al. Limitation of excessive extracellular matrix turnover may contribute to survival benefit of spironolactone therapy in patients with congestive heart failure insights from the randomized aldactone evaluation study (RALES). Circulation. 2000;102(22):2700-2706.

30. Hayashi M, Tsutamoto T, Wada A, et al. Immediate administration of mineralocorticoid receptor antagonist spironolactone prevents post-infarct left ventricular remodeling associated with suppression of a marker of myocardial collagen synthesis in patients with first anterior acute myocardial infarction. Circulation. 2003;107 (20):2559-2565. doi:10.1161/01.CIR.0000068340.96506.0F

31. Dong Q, Liu K-S, Liu H-B, et al. Effect of spironolactone on left ventricular remodeling in patients with acute myocardial infarction. Chin J Cardiol. 2005;33(4):315-319.

32. Moher D, Liberati A, Tetzlaff J, Altman DG. PRISMA group preferred reporting items for systematic reviews and meta-analyses: the PRISMA statement. PLoS Med. 2009;6:e1000097. doi:10.1371/journal.pmed. 1000097

33. Liberati A, Altman DG, Tetzlaff J, et al. The PRISMA statement for reporting systematic reviews and meta-analyses of studies that evaluate health care interventions: explanation and elaboration. PLoS Med. 2009;6(7):e1000100. doi:10.1371/journal.pmed.1000100

34. Taggart DP, DAmico R, Altman DG. Effect of arterial revascularisation on survival: a systematic review of studies comparing bilateral and single internal mammary arteries. Lancet. 2001;358:870-875. doi:10.1016/S0140-6736(01)06069-X

35. Athanasiou T, Al-Ruzzeh S, Kumar P, et al. Off-pump myocardial revascularization is associated with less incidence of stroke in elderly patients. Ann Thorac Surg. 2004;77:745-753. doi:10.1016/S00034975(03)01431-0

36. Higgins J, Thompson S, Deeks J, Altman D. Statistical heterogeneity in systematic reviews of clinical trials: a critical appraisal of guidelines and practice. J Health Serv Res Policy. 2002;7(1):51-61. doi:10.1258/1355819021927674

37. Hase M, Babazono T, Ujihara N, Uchigata Y. Comparison of spironolactone and trichlormethiazide as add-on therapy to renin-angiotensin blockade for reduction of albuminuria in diabetic patients. J Diabetes Investig. 2013;4(3):316-319. doi:10.1111/jdi.12029

38. Saudan P, Mach F, Perneger T, et al. Safety of low-dose spironolactone administration in chronic hemodialysis patients. Nephrol Dial Transplant. 2003;18(11):2359-2363. doi:10.1093/ndt/gfg388

39. Liang Y. The effects of spironolactone on LVEF and LVM in heamodialysis patients with end stage renal disease. Chin J Clinicians (Electronic Edition). 2011;18:5271-5275.

40. Lin CT, Zhang Q, Zhang HF, et al. Long-term effects of low-dose spironolactone on chronic dialysis patients: a randomized placebocontrolled study. J Clin Hypertens. 2015.

41. Matsumoto Y, Mori Y, Kageyama S, et al. Spironolactone reduces cardiovascular and cerebrovascular morbidity and mortality in hemodialysis patients. $J$ Am Coll Cardiol. 2014;63(6):528-536. doi:10.1016/j.jacc.2013.09.056
42. Ni X, Zhang J, Zhang P, et al. Effects of spironolactone on dialysis patients with refractory hypertension: a randomized controlled study. J Clin Hypertens. 2014;16(9):658-663. doi:10.1111/jch.12374

43. Taheri S, Mortazavi M, Shahidi S, et al. Spironolactone in chronic hemodialysis patients improves cardiac function. $N$ Engl $J$ Med. 2009;20(3):392.

44. Feniman-De-Stefano GMM, Zanati-Basan SG, De Stefano LM, et al. Spironolactone is secure and reduces left ventricular hypertrophy in hemodialysis patients. Ther Adv Cardiovasc Dis. 2015;9(4):158-167. doi: $10.1177 / 1753944715591448$

45. Gross E, Rothstein M, Dombek S, Juknis HI. Effect of spironolactone on blood pressure and the renin-angiotensin-aldosterone system in oligo-anuric hemodialysis patients. Am J Kidney Dis. 2005;46 (1):94-101.

46. Vukusich A, Kunstmann S, Varela C, et al. A randomized, double-blind, placebo-controlled trial of spironolactone on carotid intima-media thickness in nondiabetic hemodialysis patients. Clin J Am Soc Nephrol. 2010;5 (8):1380-1387. doi:10.2215/CJN.09421209

47. Pitt B, Remme W, Zannad F, et al. Eplerenone, a selective aldosterone blocker, in patients with left ventricular dysfunction after myocardial infarction. $N$ Engl $J$ Med. 2003;348(14):1309-1321. doi:10.1056/NEJMoa030207

48. Modena MG, Aveta P, Menozzi A, Rossi R. Aldosterone inhibition limits collagen synthesis and progressive left ventricular enlargement after anterior myocardial infarction. Am Heart J. 2001;141(1):41-46. doi: $10.1067 / \mathrm{mhj} .2001 .111258$

49. Ng KP, Arnold J, Sharif A, et al. Cardiovascular actions of mineralocorticoid receptor antagonists in patients with chronic kidney disease: a systematic review and meta-analysis of randomized trials. J Renin Angiotensin Aldosterone Syst. 2015;1470320315575849.

50. Choi HY, Ha SK. Potassium balances in maintenance hemodialysis. Electrolyte Blood Press. 2013;11(1):9-16. doi:10.5049/ EBP.2013.11.1.9

51. Noori N, Kalantar-Zadeh K, Kovesdy CP, et al. Dietary potassium intake and mortality in long-term hemodialysis patients. $\mathrm{Am}$ $J$ Kidney Dis. 2010;56(2):338-347. doi:10.1053/j. ajkd.2010.03.022

52. Agarwal R, Nissenson AR, Batlle D, et al. Prevalence, treatment, and control of hypertension in chronic hemodialysis patients in the United States. Am J Med. 2003;115(4):291-297.

53. Lorenz MW, Markus HS, Bots ML, Rosvall M, Sitzer M. Prediction of clinical cardiovascular events with carotid intima-media thickness a systematic review and meta-analysis. Circulation. 2007;115 (4):459-467. doi:10.1161/CIRCULATIONAHA.106.628875

54. O'Leary DH, Polak JF, Kronmal RA, et al. Carotid-artery intima and media thickness as a risk factor for myocardial infarction and stroke in older adults. $N$ Engl J Med. 1999;340(1):14-22. doi:10.1056/ NEJM199901073400103

55. Tsivgoulis G, Vemmos K, Papamichael C, et al. Common carotid artery intima-media thickness and the risk of stroke recurrence. Stroke. 2006;37 (7):1913-1916. doi:10.1161/01.STR.0000226399.13528.0a

56. Hammer F, Krane V, Stork S, et al. Rationale and design of the mineralocorticoid receptor antagonists in end-stage renal disease study (MiREnDa). Nephrol Dial Transplant. 2014;29(2):400-405. doi:10.1093/ndt/gft409 


\section{Publish your work in this journal}

Drug Design, Development and Therapy is an international, peerreviewed open-access journal that spans the spectrum of drug design and development through to clinical applications. Clinical outcomes, patient safety, and programs for the development and effective, safe, and sustained use of medicines are a feature of the journal, which has also been accepted for indexing on PubMed Central. The manuscript management system is completely online and includes a very quick and fair peer-review system, which is all easy to use. Visit http://www. dovepress.com/testimonials.php to read real quotes from published authors. 